\title{
Alphonse Tonyè, Critique et réception des littératures francophones
}

\section{Emanuela Cacchioli}

\section{(2) OpenEdition}

1 Journals

\section{Edizione digitale}

URL: http://journals.openedition.org/studifrancesi/1482

DOI: ERREUR PDO dans/localdata/www-bin/Core/Core/Db/Db.class.php L.34 : SQLSTATE[HYO00]

[2006] MySQL server has gone away

ISSN: 2421-5856

\section{Editore}

Rosenberg \& Sellier

\section{Edizione cartacea}

Data di pubblicazione: 1 décembre 2015

Paginazione: 636-637

ISSN: 0039-2944

\section{Notizia bibliografica digitale}

Emanuela Cacchioli, «Alphonse Tonyè, Critique et réception des littératures francophones», Studi Francesi [Online], 177 (LIX | III) | 2015, online dal 01 décembre 2015, consultato il 08 janvier 2021. URL: http:// journals.openedition.org/studifrancesi/1482 ; DOI: https://doi.org/10.4000/studifrancesi.1482

Questo documento è stato generato automaticamente il 8 janvier 2021.

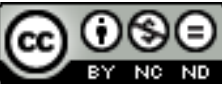

Studi Francesi è distribuita con Licenza Creative Commons Attribuzione - Non commerciale - Non opere derivate 4.0 Internazionale. 


\title{
Alphonse Tonyè, Critique et réception des littératures francophones
}

\author{
Emanuela Cacchioli
}

\section{NOTIZIA}

ALPHONSE TONYÈ (sous la direction de), Critique et réception des littératures francophones, Paris, L'Harmattan, 2013, pp. 340.

1 Nel novembre del 2006, all'università di Yaoundé in Camerun, si è tenuto un convegno dal titolo «Critique et réception des Littératures francophones 33 ans après», i cui interventi sono stati ora riuniti in volume. L'indicazione temporale riferita ai 33 anni mostra la volontà di porsi in continuità tematica e euristica con un altro convegno che si era tenuto nel 1978 e che ruotava sempre attorno alla ricezione critica della letteratura africana. Lo scopo del convegno del 2006 è quello di interrogarsi sui testi letterari "del Sud" e di considerarli per la loro portata poetica, i saperi che veicolano, la mediazione che viene compiuta durante la lettura e la ricezione da parte di pubblici diversi.

Il volume è suddiviso in tre sezioni. La prima contiene alcuni contributi generali che inquadrano, a livello teorico, la questione della ricezione critica delle letterature francofone. Richard Laurent OMGBA, Existe-t-il une littérature francophone? Statut et ambiguité de l'écriture en francophonie (pp.13-22), si concentra sulla definizione di un campo letterario francofono che esiste come spazio dialettico, ma che è difficile da circoscrivere attraverso altre categorie. Le letterature francofone si caratterizzano per una pluralità di codici estetici e di lingue (parliamo di diglossia o addirittura di poliglossia). Anche le infrastrutture letterarie faticano a rendersi autonome da Parigi, intesa come luogo simbolico catalizzatore. L'unico modo per svincolarsi da queste dinamiche consiste nell'approcciare le letterature francofone per mezzo dell'etnocritica, ossia con una modalità che intende analizzare e interpretare le similitudini e le differenze tra culture diverse. Segue l'articolo di Désiré NYELA, 
Littérature africaine? Certes, mais de quelle littérature parle-t-on? (pp. 23-38), che esamina le varie etichette applicate alle letterature africane e individua la modalità comparativa circoscritta a un corpus limitato di testi al fine di cogliere le analogie estetiche. Paul ZANG ZANG, con La question linguistique chez les écrivains francophones africains (pp. 39-62), prende in considerazione la questione linguistica e la produzione letteraria a partire da tre momenti storici: prima dell'indipendenza, dopo tale evento e dopo il Duemila.

3 La seconda parte è centrata su considerazioni estetiche. Alphonse TONYÈ, Généricité et transgénéricité dans "Les arbres en parlent encore" de Calixthe Beyala (pp. 65-82), si focalizza sul romanzo della scrittrice camerunense e ne analizza il contesto dell'enunciazione, dell'enunciato e del significato. Il contributo di Jean-Claude Azoumaye, La lecture déconstructive d'une allégorie héroïque, de "L'Ounbangui Chari à la Rochelle" de Pierre Sammy Mackfoy (pp. 83-96), esamina la decostruzione del modello occidentale dell'eroe e la sua ricontestualizzazione africana. In Narrativité et mondialisation adverbiale dans "Brouillons de vie" de Angéline Solange Bonono (pp.97-108), Christiane Félicité EWANE analizza l'uso dell'avverbio in relazione alle altre parti del discorso e come vettore di informazione all'interno della strategia narrativa. Gérard-Marie Noumssi, La poétique de l'ambivalence dans "L'aventure ambiguë" de Cheickh Hamidou Kane (pp.109-132), si sofferma sull'originalità dello scrittore senegalese e sul suo testo che sfugge alle categorizzazioni ascrivibili alle grammatiche classiche. Con De la langue des auteurs au discours des critiques: la littérature camerounaise locale en devenir (pp. 133-141), Charles BELINGA B'ENO constata che, fino ad ora, la critica ha approcciato le letterature del Sud in modo improvvisato, come avviene sempre di fronte a un nuovo fenomeno letterario. Il passaggio successivo è quello di definire una direzione e di trovare una propria coerenza interna. Dal canto suo, Alpha Noël MALONGA, Migritude et auctoréférentialité ou la littérature africaine francophone entre l'Afrique et l'Occident (pp.143-156), rileva l'importanza della biografia e della psicologia degli autori e le ripercussioni di questi aspetti sulle loro opere. Il critico vuole mettere in luce come la letteratura africana sia frutto di esperienze individuali e non solo di prese di posizioni collettive. Con l'articolo "Le corps, le sexe et l'amour": l'érotisation de l'écriture poétique dans "Boulevard de la liberté" de Dati, d'Almeida, Perri, et Yamguen (pp.157-170), NDE analizza un'opera nata dalla collaborazione di diversi autori che si sono accordati per trattare lo stesso soggetto all'interno della medesima opera e a partire da scelte estetiche comuni. Patricia BISSA ENAMA, La poétique du "regard" dans "Trop de soleil tue l'amour" de Mongo Beti (pp. 171-191), invece, rintraccia la metamorfosi del soggetto narrante attraverso l'analisi dello sguardo che lui stesso scambia con gli altri personaggi.

4 La terza parte, dedicata agli snodi letterari, si apre con il contributo di Joseph DoNG AROGA, Du statut d'auteur en littérature orale (pp. 195-207). Il critico riflette sul cambiamento di statuto dell'autore quando ci muoviamo all'interno della letteratura orale: da co-autore, esecutore, oggi è divenuto autore a tutti gli effetti e rivendica la paternità delle sue opere. In Les voix du silence dans "La Mémoire amputée" de Were Were Liking (pp. 209-225), Alice Delphine TANG analizza il romanzo della scrittrice camerunense che rompe il silenzio per colmare i vuoti che segnano la storia del suo paese. Le nozioni di spazio fisico, spazio evocato e la rappresentazione dell'universo rurale e urbano sono gli argomenti del saggio di Marie-Rose ABOMO-MAURIN, Le roman camerounais: topographie, espace physique et espace vécu (pp.227-244). Con Poésie camerounaise et critique en francophonie: le cas de "Balafon" d'Engelbert Mveng (pp. 245-249), Mathilde zoA dedica la sua attenzione alla poesia e alle forme estetiche che ha assunto 
nelle letterature africane. Anche il contributo di Désiré ATANGANA KounA, L'immigration, l'ici et l'ailleurs chez quelques romanciers camerounais postcoloniaux (pp. 251-262), si sofferma sull'individuazione di tendenze comuni. Il suo studio prende in esame il genere narrativo e le nozioni di "ici" e "ailleurs". Con L'état postcolonial africain dans l'œuvre dramatique d'Aimé Césaire (pp. 263-293), Gérard-Marie MEssina sceglie invece il genere teatrale e, nello specifico, le opere di Césaire e ne mette in rilievo la portata storica e poetica. Antoine-Guillaume MAKANI, Le chronotope de l'enfer dans le roman francophone d'Afrique centrale (pp. 275-293), analizza la dimensione spazio-temporale, la simultaneità dei due aspetti e la loro interazione reciproca. L'articolo di Joseph ABAH ATANGANA, "Fils de prélat" d'Armand Claude Abanda: une astuce éditoriale (pp. 295-305), esamina la scrittura innovatrice e sovversiva dello scrittore camerunense. Anche Élodie Carine TANG si sofferma sull'originalità estetica della scrittura di una giovane autrice nel suo contributo dal titolo: L'exorcisme comme prétexte de dévoilement des réalités des familles africaines dans "Ménages d'Afrique" de Ch. Julie Nlènd (pp. 307-316). Chiude la collettanea Emmanuel KAMDEM FOPA, Réception des littératures francophones en classe de "french" au Cameroun: fortunes diverses des genres (pp.317-324), che sceglie una prospettiva inedita. Il critico si sofferma infatti sulla ricezione anglofona (e la mediazione discorsiva che ne viene fatta) di testi francofoni.

5 Sebbene il volume si presenti come uno studio della ricezione critica delle letterature francofone, l'attenzione dei contributi si focalizza quasi esclusivamente sulle letterature africane e, all'interno di queste, soprattutto sulla letteratura camerunense, la cui ricezione può comunque offrire uno spunto di riflessione importante per l'intero fenomeno. 